\title{
Efek pH Terhadap Pelepasan Fosfat Oleh Lumpur Aktif Dalam Kondisi Anaerob
}

\section{The Effect of pH on Phosphate Released By Activated Sludge Under Anaerobic Condition}

\author{
Jubhar Christian Mangimbulude \\ Pusat Studi Manajemen Lingkungan dan Bioteknologi \\ Fakultas Biologi-Universitas Kristen Satya Wacana, Salatiga \\ E-mail: Jub@uksw.edu
}

\begin{abstract}
Phosphate removal in domestic wastewater or industrial wastewater is a key factor of prevent eutrophication. Mechanisms of biological phosphate removal occurs under both of anaerobic and aerobic conditions. Phosphate up take under aerobic condition is much determined by phosphate released under anaerobic condition. The objective of this research was to understand the effect of various of external $\mathrm{pH}$ on phosphate released by activated sludge under anaerobic conditions. For that purpose, the experiments were conducted in batch system under anaerobic condition at pH of 6.0, 7.0, 8.0 and 9.0 separetely. $\mathrm{PO}_{4}$, Acetate and MLVSS were measured and used as parameters to analyze process. The results shown that the highest of phosphate released and acetate consumed occurred at pH 9.0 and the lowest it was occurred at pH 6.0. The value of phosphate/acetate ratio was calculated to be in variation of 0.161 to $0.256 \mathrm{p}$-mol/C-mol in $\mathrm{pH}$ range of 6.0 to 9.0
\end{abstract}

Key words : released phosphate, activated sludge, wastewater

Diterima: 16 September 2002, disetujui 20 April 2003

\section{Pendahuluan}

Pengurangan fosfat pada air limbah domestik maupun industri merupakan faktor kunci untuk mencegah eutrofikasi di badanbadan air. Pengurangan fosfat secara biologis merupakan salah satu alternatif yang banyak digunakan karena relatif murah biaya operasionalnya, dan kualitas effluent yang dihasilkan relatif aman bagi lingkungan.

Prinsip pengurangan fosfat melalui proses lumpur aktif didasarkan pada sifat-sifat biokimia dan fisiologi mikroorganisme yang bertanggung-jawab terhadap pengambilan fosfat (Toerien, et al.,1986).

Mekanisme pengurangan fosfat secara biologi diawali dengan pelepasan fosfat oleh P-removing sludge keluar sel kemudian dilanjutkan dengan pengambilan fosfat di luar sel ketika substrat di luar sel tidak digunakan lagi atau telah habis. Pelepasan fosfat berlangsung dalam kondisi anaerob, sementara pengambilan fosfat berlangsung dalam kondisi aerob (Sedlak, 1991).

Dalam kondisi anaerob P-removing sludge menggunakan asam asetat dan mengubah serta menyimpan dalam bentuk poli -hidroksi-butirat (PHB) yang digunakan sebagai substrat cadangan. Pengambilan substrat di luar sel (asetat) memerlukan energi, yang diperoleh dari hidrolisis polifosfat Konsekuensi dari metabolisme tersebut adalah fosfat akan dilepas keluar sel (Smolder, et al.,1994). Skema metabolisme pelepasan fosfat dalam kondisi anaerob dapat dilihat pada Gambar 1.

Dalam kondisi anaerob pengambilan asetat dan hidrolisis polifosfat merupakan 
reaksi berpasangan, sehingga rasio antara fosfat yang dilepas dan asetat yang digunakan (rasio P/C-HAc) merupakan perameter kunci dalam mengontrol pengurangan fosfat (Smolder 1995). Jenkis dan Tandoi dalam Smolder (1995) melaporkan bahwa nilai rasio P/C-HAc berkisar antara 0,25-0,75 mol-P/molC.

Dalam upaya optimalisasi proses pengurangan fosfat diperlukan strategi khusus guna mempertinggi kemampuan metabolisme oleh P-removing sludge. Strateginya berupa modifikasi lingkungan untuk mempertinggi kemampuan P-removing sludge dalam melepaskan fosfat pada kondisi anaerob. Potensial redoks, temperatur dan $\mathrm{pH}$ berpengaruh terhadap pelepasan fosfat keluar sel (Toerien, et al.,1998; Smolder ,et al.,1994).

Studi pengaruh $\mathrm{pH}$ terhadap pelepasan fosfat dalam kondisi anaerob belum banyak dilakukan. Oleh karena itu tujuan penelitian ini adalah mengetahui efek $\mathrm{pH}$ terhadap pelepasan fosfat secara biologis dalam kondisi anaerob. Diduga bahwa dengan adanya perubahan gradien $\mathrm{pH}$ di luar sel ( $\mathrm{pH}$ ekternal ) mempengaruhi transfer asetat ke dalam sel, sehingga mempengaruhi jumlah fosfat yang dilepas dan rasio P/C-HAc.

\section{Metode Penelitian}

\section{Medium}

Medium sintetik dengan komposisi per liter mengandung; 0,85 NaAc. $3 \mathrm{H}_{2} \mathrm{O}$ (400 mg COD /l) sebagai sumber karbon, $107 \mathrm{mg} \mathrm{NH}_{4} \mathrm{Cl}$, (28 $\mathrm{mg}-\mathrm{N} / \mathrm{I}), 75,5 \mathrm{mg} \mathrm{NaH} \mathrm{NO}_{4} \cdot 2 \mathrm{H}_{2} \mathrm{O}(15 \mathrm{mg}-$ $\mathrm{P} / \mathrm{I}), 90 \mathrm{mg} \mathrm{MgSO}{ }_{4} 7 \mathrm{H}_{2} \mathrm{O}, 36 \mathrm{mg} \mathrm{KCI}, 41 \mathrm{mg}$ $\mathrm{CaCl}_{2} \cdot 2 \mathrm{H}_{2} \mathrm{O} ; 1 \mathrm{mg}$ yeast extract, $0,3 \mathrm{ml}$ larutan nutrien (per liter mengandung; $1,5 \mathrm{~g} \mathrm{Fe} \mathrm{CI}_{3}$. $6 \mathrm{H}_{2} \mathrm{O} ; 1,5$ g. $\mathrm{H}_{3} \mathrm{BO}_{3} 0,03 \mathrm{~g} \mathrm{CuSO}_{4} 5 \mathrm{H}_{2} \mathrm{O}$; $0,18 \mathrm{~g} \mathrm{KI} ; 0,12 \mathrm{~g} \mathrm{Mn} \mathrm{CI}_{2} 4 \mathrm{H}_{2} \mathrm{O} ; 0,06 \mathrm{~g}$ $\mathrm{Na}_{2} \mathrm{MOO}_{4} 2 \mathrm{H}_{2} \mathrm{O} ; 0,12 \mathrm{~g} \mathrm{ZnSO}_{4} .7 \mathrm{H}_{2} \mathrm{O} ; 0,15 \mathrm{~g}$ $\mathrm{COCI}_{2} \cdot 6 \mathrm{H}_{2} \mathrm{O}$ dan $10 \mathrm{~g}$ EDTA).

\section{Phosphate $(P)$-removing Sludge}

$P$-removing sludge yang digunakan diperoleh dari Laboratorium Environmental Engineering, IHE-Delft.

\section{Prosedur percobaan}

Percobaan dilakukan dengan sistem curah, caranya sebagai berikut 1,25 L medium sintetik dimasukkan ke dalam reaktor yang berisi 1,25 L kultur P-removing sludge sehingga total volume menjadi 2,5 L. Temperatur diatur konstan $20^{\circ} \mathrm{C}$ menggunakan termostat, $\mathrm{pH}$ diatur sesuai perlakukan $(\mathrm{pH} \quad 6,0 ; 7,0 ; 8,0$ dan 9,0) dan dijaga konstan dengan cara menambahkan larutan $0,5 \mathrm{~N} \mathrm{NaOH}$ dan atau $0,5 \mathrm{~N} \mathrm{HCI}$ secara automatis lewat pompa peristaltik. Pengaduk dalam reaktor dijalankan pada kecepatan $500 \mathrm{rpm}$. Gas $\mathrm{N}_{2}$ dialirkan ke dalam reaktor berkecepatan $30 \mathrm{~L} / j a m$ guna membuat kondisi di dalam reaktor anaerob yang dipertahankan selama 300 menit. Pengambilan sampel dilakukan selama interval waktu tertentu, untuk mengukur konsentrasi fosfat, asam asetat, mixed liquor suspended solid (MLSS) dan mixed liquor volatile suspended solid (MLVSS). MLSS dan MLVSS diukur sesuai prosedur APHA, 1992. Asetat diukur dengan gas kromatografi (Haycep Q80 -100 mesh column, temperatur injeksi dan FIS $270{ }^{\circ} \mathrm{C}$ dan $300{ }^{\circ} \mathrm{C}$ ). Fosfat diukur dengan Autoanalyzer berdasarkan metoda asam askorbik (APHA, 1992)

\section{Hasil dan Pembahasan}

Hasil menunjukkan bahwa dinamika pelepasan fosfat dan penggunaan asetat oleh $P$-removing sludge dipengaruhi oleh $\mathrm{pH}$ eksternal. Secara keseluruhan, terlihat bahwa dengan meningkatnya $\mathrm{pH}$ eksternal, fosfat yang dilepas juga meningkat (Gb. 2).

Gambar 2 menunjukkan bahwa laju pelepasan fosfat oleh $P$-removing sludge pada semua perlakuan paling cepat selama 60 menit pertama, lalu melambat. Bahkan pada perlakuan $\mathrm{pH} 7,0$ dan 8,0 setelah menit ke 60 fosfat tidak dilepaskan lagi. Pelepasan fosfat tertinggi terjadi pada $\mathrm{pH} 9,0$ sebesar $72,4 \mathrm{mg}$ $\mathrm{PO}_{4}-\mathrm{P} / \mathrm{grVSS}$, dan terendah pada $\mathrm{pH}$ 6,0 sebesar $29,7 \mathrm{mg} \mathrm{PO}_{4}-\mathrm{P} / \mathrm{grVSS}$. Fosfat yang dilepas meningkat signifikan bila $\mathrm{pH}$ eksternal meningkat. Demikian juga asetat yang dikonsumsi (Gambar 3). Jika dihubungkan antara konsentrasi fosfat yang dilepas dan atau asetat yang dikonsumsi dengan $\mathrm{pH}$ tampak 
meningkat secara linier (Gambar 4), keseluruhan data konsentrasi fosfat yang dilepaskan pada setiap $\mathrm{pH}$ disajikan dalam Tabel 1.

Hasil tabel.1. membuktikan bahwa konsentrasi fosfat yang dilepaskan di tentukan oleh jumlah asetat yang dikonsumsi. Fosfat cenderung dilepaskan terus selama konsumsi asetat terus berlangsung. Ketika asetat tidak dikonsumsi, pelepasan fosfat terhenti (Gambar 2 dan 4). Hal ini didukung oleh beberapa peneliti sebelumnya (Arun et al., 1988; Toerien et al., 1990; Wentzel et al., 1985). Smolder (1995) menyebutkan bahwa pelepasan fosfat dan konsumsi asetat merupakan reaksi berpasangan, artinya fosfat yang dilepas merupakan konsekuensi metabolisme dari transfer asetat ke dalam sel. Perhitungan rasio P/C-HAc menunjukkan bahwa meningkatnya pH eksternal akan meningkatkan nilai rasio P/C-HAc (Gambar 5). Nilai rasioP/C-HAc pada $\mathrm{pH}$ 5,0 sampai $\mathrm{pH}$ 9,0 yang pernah dilaporkan oleh Smolder et al., (1994) dalam percobaannya adalah berkisar antara 0,25 0,75 mol-P/mol-C-Hac, yang lebih tinggi daripada penelitian ini.

Pelepasan fosfat dalam kondisi anaerob bergantung pada $\mathrm{pH}$ eksternal. Secara metabolisme dan bioenergitik, fenomena tersebut dapat dihubungkan dengan transfer asetat ke dalam sel. Smolder et al., (1994) melaporkan bahwa transfer asetat ke dalam sel membutuhkan energi sebesar $\pm 0,5$ mol ATP per mol C-HAc. Energi tersebut tidak konstan melainkan tergantung pada $\mathrm{pH}$, dengan demikian perubahan $\mathrm{pH}$ menyebabkan terjadinya perubahan potensial elektrik pada membran sel. Asumsi bahwa $\mathrm{pH}$ dalam dan proton motive force (pmf) dalam sel konstan maka perbedaan potensial elektrik fungsi $\mathrm{pH}$ dapat dihitung melalui persamaan di bawah ini:

$\Delta \psi=\Delta \mathrm{p}+2,3$ R.T (pH eksternal - $\mathrm{pH}$ internal $)=\Delta \mathrm{p}+2,3$ R.T. $\Delta \mathrm{pH}(\mathrm{Kj} / \mathrm{mol})$ (Smolder., et al., 1994))

\section{Keterangan:}

$\Delta \psi \quad$ : Perbedaan potensial elektrik $(\mathrm{Kj} / \mathrm{mol})$

$\Delta \mathrm{p} \quad$ : Proton motive force $(\mathrm{pmf})(\mathrm{KJ} / \mathrm{mol})$

$\mathrm{R} \quad$ : Konstanta gas $(\mathrm{Kj} / \mathrm{K} . \mathrm{mol})$

$\mathrm{T}$ : Temperatur
Apabila $\mathrm{pH}$ di luar sel lebih rendah dari $\mathrm{pH}$ internal, maka $\Delta \mathrm{pH}$ menjadi positif, sehingga pmf menjadi rendah. Akibatnya energi yang tersedia relatif sedikit dan berpengaruh terhadap kuantitas asetat yang ditransfer ke dalam sel. Sebaliknya apabila $\mathrm{pH}$ eksternal lebih tinggi dari $\mathrm{pH}$ internal, $\Delta \mathrm{pH}$ di negatif, $\Delta \psi$ tinggi dan pmf konstan. Akibatnya, energi yang tersedia menjadi tinggi dan kuantitas asetat yang ditransfer ke dalam sel lebih banyak.

\section{Kesimpulan}

Kesimpulan dari penelitian ini adalah

1. Pelepasan fosfat oleh P-removing sludge dalam kondisi anaerob sangat dipengaruhi oleh perubahan $\mathrm{pH}$.

2. Fosfat yang dilepas tertinggi pada $\mathrm{pH} 9,0$ dan terendah pada $\mathrm{pH}$ 6,0.

3. Konsumsi asetat tertinggi terjadi pada $\mathrm{pH}$ 9,0 dan terendah terjadi pada $\mathrm{pH} 6,0$.

4. Rasio P/C-HAc mengalami pertambahan secara signifikan dari $\mathrm{pH} 6,0-\mathrm{pH} 9,0$ dengan kisaran nilai dari $0,161-0,256$.

\section{Daftar Pustaka}

APHA. 1992. Standard Method For The examination of Waste and Wastewater. $18^{\text {th }}$. American Public Health Association. Washington.DC.

Arun, V., Mino, T., and Matsuo, T. 1988. Biological Mechanisms of Acetate Uptake Mediated by Carbohydrate Consumption In Excess Phosphorous Removal System. Wat.Res. 22(5):565570.

Sedlak, R.I. 1991. Phosphorous And Nitrogen Removal From Manucipal Wastewater. Principles and Practice. Second editions. Lewis Publisher.

Smolder, G.J.F.1995. A Metabolic Model of The Biological Phosphorous Removal: Stoichiometry, kinetics and dynamic behaviour. Ph.D. thesis University of Technology. Delft. 
Smolder, G.J.F., J. van der Meij., and M.C.M. van Loosdrecht.1994. Model of The Anaerobic Metabolisms of The Biological Phosphorous Removal Process: Stoichiometry and $\mathrm{pH}$ influence. Biotech and Bioeng. 43: 461470 .

Wentsel, M.C., Dold, P.L., Ekama, G.A., Marais, G.V.R. 1986. Kinetics of Biological Phosphorous Release. Wat.Sci.Tech.17: 57-71.
Toerien, F.T., Gerber,A., Lotter, L.H., Cloete, T.E. 1990. Enhanched Biological Phosphorous Removal in Activated Sludge System. Advances in Microbial Ecology. Marshall.K.C.11: 172-230.

Toerien, F.T and K.E.U. Brodisch. 1986. Biological Phosphate Removal in Activated Sludge System.Wat.Res. 12(4): 66-73.

Tabel 1. Efek $p H$ pada pelepasan fosfat oleh lumpur aktif pada kondisi anaerob

\begin{tabular}{lcccc}
\hline \multirow{2}{*}{ Parameter } & \multicolumn{4}{c}{ Perlakuan $\mathbf{p H}$} \\
\cline { 2 - 5 } & $\mathbf{6 , 0}$ & $\mathbf{7 , 0}$ & $\mathbf{8 , 0}$ & $\mathbf{9 , 0}$ \\
\hline \hline Fosfat yang dilepas (mgP-PO $/$ /grVSS) & 29,7 & 45,7 & 58,7 & 72,4 \\
Asetat yang dikonsumsi (mgC-HAc/grVSS) & 71,2 & 83,9 & 92,1 & 109,2 \\
Rasio P/C-HAc & 0,161 & 0,210 & 0.246 & 0,256 \\
\hline
\end{tabular}

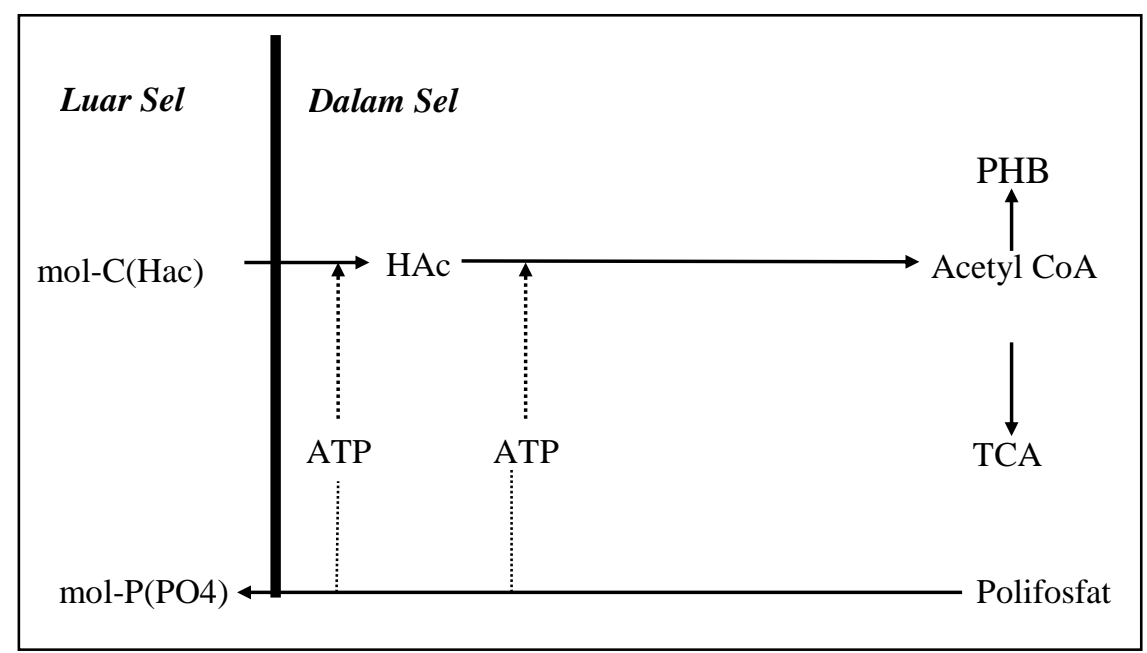

Gambar 1. Metabolisme pelepasan fosfat dalam kondisi anaerob (Smolder,1995) 


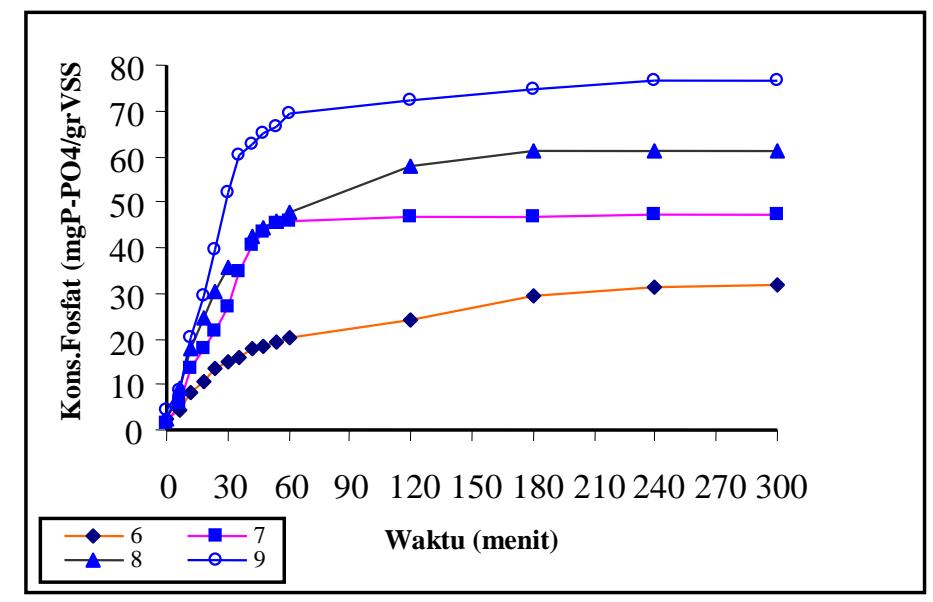

Gambar 2. Konsentrasi fosfat yang dilepaskan pada variasi pH dalam kondisi anaerob

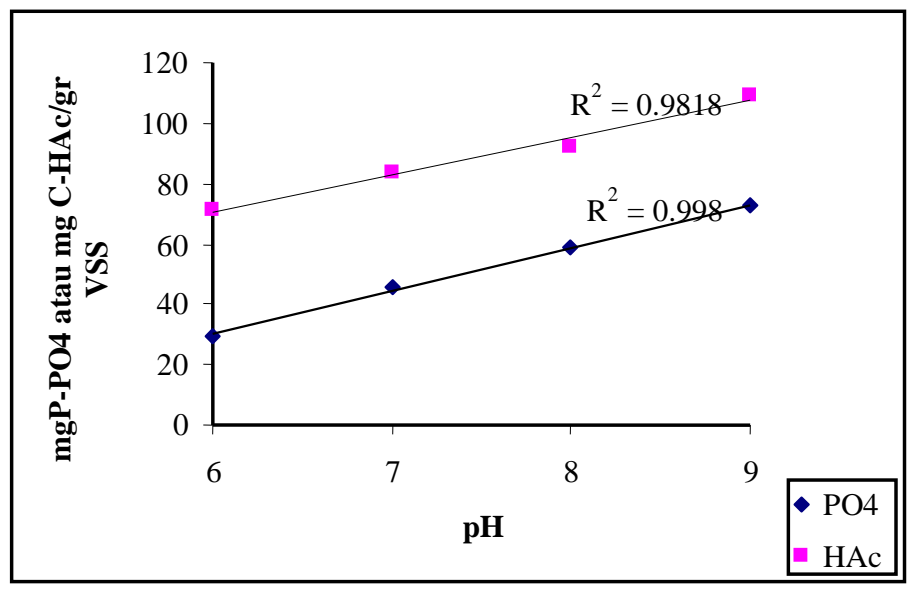

Gambar 3 . Hubungan antara fosfat yang dilepaskan, asetat yang dikonsumsi dengan pH 


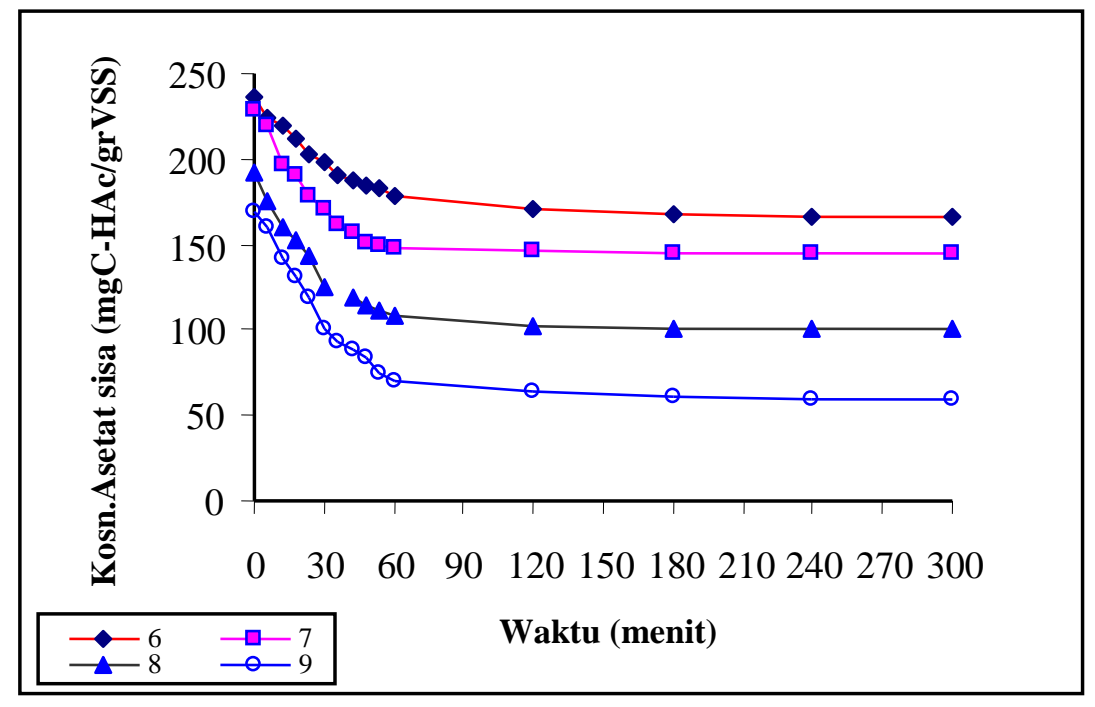

Gambar 4. Konsentrasi asetat sisa pada variasi $p H$

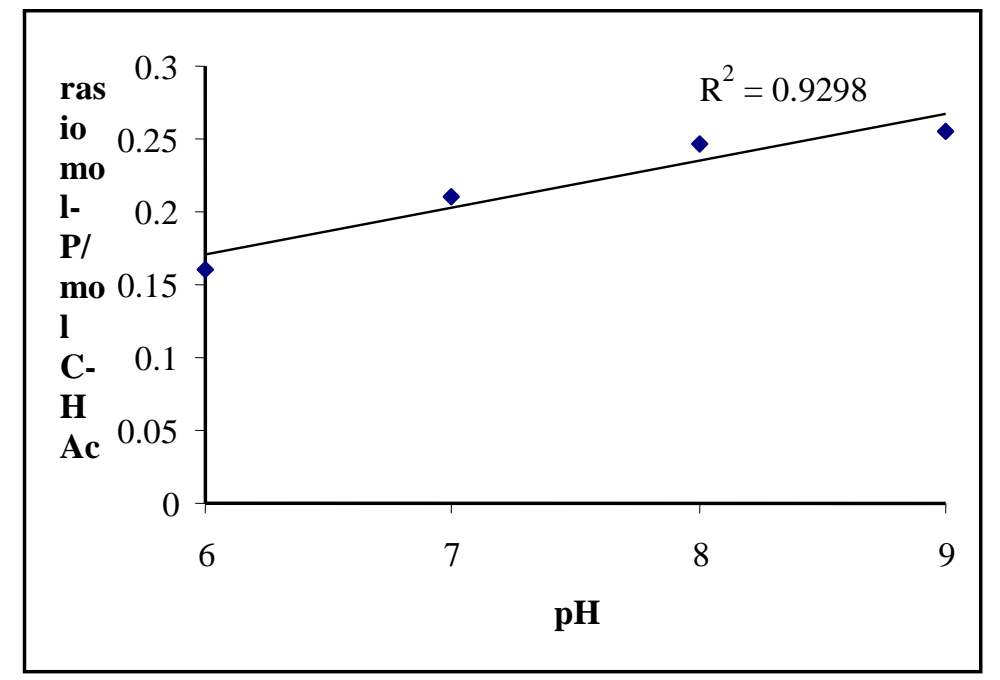

Gambar 5. Hubungan antara rasio P/C-HAc dengan variasi $\mathrm{pH}$ 